\title{
Adolescents' Exposure to a Sexualized Media Environment and Their Notions of Women as Sex Objects
}

\author{
Jochen Peter • Patti M. Valkenburg
}

Published online: 28 February 2007

(C) Springer Science + Business Media, LLC 2007

\begin{abstract}
This study was designed to investigate whether adolescents' exposure to a sexualized media environment is associated with stronger beliefs that women are sex objects. More specifically, we studied whether the association between notions of women as sex objects and exposure to sexual content of varied explicitness (i.e., sexually nonexplicit, semi-explicit, or explicit) and in different formats (i.e., visual and audio-visual) can be better described as cumulative or as hierarchical. Further, we investigated whether this association was contingent on gender. Based on data from an on-line survey of 745 Dutch adolescents aged 13 to 18 , we found that the relationship between exposure to a sexualized media environment and notions of women as sex objects followed a hierarchical pattern: Starting with adolescents' exposure to sexually semiexplicit content, the statistical significance of the relationship with notions of women as sex objects moved from semi-explicit to explicit sexual content and from visual to audio-visual formats. Exposure to sexually explicit material in on-line movies was the only exposure measure significantly related to beliefs that women are sex objects in the final regression model, in which exposure to other forms of
\end{abstract}

\author{
J. Peter P. M. Valkenburg \\ University of Amsterdam, \\ Amsterdam, The Netherlands \\ P. M. Valkenburg \\ e-mail: p.m.valkenburg@uva.nl \\ J. Peter $(\bowtie)$ \\ The Amsterdam School of Communications Research, \\ University of Amsterdam, \\ Kloveniersburgwal 48, \\ 1012 CX Amsterdam, The Netherlands \\ e-mail: j.peter@uva.nl
}

sexual content was controlled. The relationship between exposure to a sexualized media environment and notions of women as sex objects did not differ for girls and boys.

Keywords Pornography · Television · Magazines ·

Internet $\cdot$ Adolescents

In the past three decades, evidence has accumulated that adolescents' exposure to sexual media content is related to a variety of gender stereotypes and sexual beliefs (for reviews, see Escobar-Chaves et al., 2005; Ward, 2003). Earlier researchers typically studied sexual content in a single genre (e.g., soap operas, comedies, dramas, or music videos) or a single medium (e.g., television or magazines; for reviews, see Escobar-Chaves et al., 2005; Ward, 2003). To capture adolescents' media experience more adequately, researchers have recently included multiple genres (Aubrey, Harrison, Kramer, \& Yellin, 2003; Ward, 2002; Ward \& Friedman, 2006) and multiple media (e.g., Brown et al., 2006; L'Engle, Brown, \& Kenneavy, 2006; Pardun, L'Engle, \& Brown, 2005).

Despite this fruitful development in the field, two gaps in the existing research are striking. First, researchers have hardly focused on adolescents' exposure to sexually explicit material on the internet as an additional correlate of adolescents' sexual beliefs. On the internet, explicit depictions of different sexual activities (e.g., oral, vaginal, and anal sex) and sexual preferences (e.g., sado-masochistic sex, fetishes) are not only easily accessible to adolescents (Cooper, 1998), they also use it (Lo \& Wei, 2005; Peter \& Valkenburg, 2006). Second, it is still an open question whether and to what extent adolescents' notions of women as sex objects are dependent on the sexual explicitness and the visual or audio-visual format of the content. Little is known about whether adolescents' consumption of, for 
example, sexually explicit content is more strongly associated with their sexual beliefs than is their exposure to sexually non-explicit content. Similarly, we do not know whether a potential association between sexual content and sexual beliefs differs between visual formats (e.g., pictures in magazines or on the internet) and audio-visual formats (e.g., movies on television or on the internet).

As a consequence of these two gaps, Brown et al. (2006) have suggested that "[a]dditional research on the effects of the media on adolescent sexuality should include exposure to Internet pornography" (p. 1026). Brown et al. have also requested that "[s]ubsequent analyses should look more closely to determine the relative influence of each of the component media [of the sexual media diet measure] on adolescents' sexual behavior" (p. 1026). In this study, we tried to address these two requests. Based on the sexual media diet measure by Brown et al. and ideas by other researchers (Brown, 2000; Brown et al., 2006; Greenfield, 2004; L'Engle et al., 2006; Pardun et al., 2005; Strasburger \& Donnerstein, 1999), we propose the concept of a sexualized media environment to extend this line of research. In response to Brown et al.'s (2006) requests, we investigated whether adolescents' exposure to sexually explicit material, particularly on the internet, is linked with their sexual beliefs in addition to their exposure to sexual content of varied sexual explicitness in other media. Further, we studied how exposure to sexual content is associated with sexual beliefs depending on the sexual explicitness of the content, the visual and audio-visual format of the material, and adolescents' gender.

The present study focused on adolescents' beliefs that women are sex objects as a sexual belief that is potentially related to exposure to sexual content in the media. The sexual objectification of women is both a theoretically and a socially relevant construct: It further develops the notion of the body as a social construction and points to a central form of gender discrimination (Fredrickson \& Roberts, 1997). Further, recent research has established a link between exposure to media coverage that sexually objectifies women and adolescents' beliefs that women are sex objects (Ward, 2002; Ward \& Friedman, 2006). Pursuit of this line of research in the aforementioned direction may help us to understand the relation between exposure to sexual media content and tendencies toward gender discrimination.

\section{Sexualized Media Environment}

There is growing consensus that adolescents live in a media-saturated world (Qrius, 2005; Roberts, Foehr, \& Rideout, 2005) and are likely to be exposed to sexual content across various media (Kunkel, Eyal, Finnerty, Biely, \& Donnerstein, 2005; Pardun et al., 2005). As a result, researchers have turned away from measuring adolescents' exposure to only a single medium. This development is best embodied by Brown et al.'s sexual media diet measure, which links adolescents' exposure to various media with the sexual content found in these media (Brown et al., 2006; L'Engle et al., 2006; Pardun et al., 2005). In an initial attempt to extend this measure into the direction of ecological models of adolescent sexuality, which view adolescents' attitudes and behavior as a result of their interactions with their environment (Lerner \& Castellino, 2002), we put forward the concept of adolescents' sexualized media environment. The concept of a sexualized media environment is based on three assumptions. First, there is an unprecedented amount of sexual content in the media. Second, this sexual content is pervasive and not limited to a single medium. Third, the various media offer easy access to increasingly explicit sexual content. This applies particularly to the internet.

Regarding the first assumption, evidence has accumulated that the sexual content in the media has increased in the recent decades (for a review, see Ward, 2003). This is particularly true for television (e.g., Kunkel et al., 2005), but also applies to general interest and girls' magazines (Carpenter, 1998; Scott, 1986). A recent US study showed that the number of sexual scenes in US television has nearly doubled between 1998 and 2005 (Kunkel et al., 2005). Others have reported that the number of pornographic pages on the internet has increased by $1,800 \%$ between 1998 and 2004 (Paul, 2005).

Is sexual media content pervasive in the sense that a notable amount of sexual content is available in the various media (second assumption)? Reviews of the literature suggest that, regardless of whether adolescents turn to print or audiovisual media, they have the chance to encounter sexual content (Escobar-Chaves et al., 2005; Ward, 2003). For example, between October 2004 and April 2005, 70\% of the 20 television shows that US adolescents watch most often included sexual content, and $45 \%$ featured sexual behavior. Ninety-two percent of the movies, $87 \%$ of the sitcoms and drama series, and $85 \%$ of the soap operas studied contained sexual content (Kunkel et al., 2005). Many magazines confront readers with provocatively posed or nude models, openly discuss sexual techniques, and advise readers on how to improve their sex lives (for a review, see Ward, 2003). And a simple search in Google with the terms "free sex" elicited, in November 2006, $2,460,000$ hits that could transport the user with one mouse click into sexually explicit sites.

The aforementioned examples of the increase and pervasiveness of sexually explicit material on the internet already support the third assumption that adolescents currently can obtain sexually explicit material in addition to sexually nonexplicit material. With the expansion of the internet, the 
sexual content available to adolescents has become more explicit. More important, on the internet adolescents can access a considerable amount of sexually explicit material anonymously and without charge (Cooper, 1998). Finally, the internet enables adolescents to create parts of their sexualized media environment themselves by sharing sexually explicit content with their peers (Greenfield, 2004).

In line with the assumptions of the concept of a sexualized media environment, then, available data suggest that adolescents may currently be confronted with an unprecedented amount of sexual media content, which is pervasive and not limited to a single medium. The internet, in particular, has sexualized adolescents' media environment by extending the explicitness of sexual content available (Cooper, 1998; Lo \& Wei, 2005; Paul, 2005).

To capture adolescents' exposure to sexual media content of varied explicitness across different media, we dealt in the present study with their consumption of sexually non-explicit, sexually semi-explicit, and sexually explicit content in magazines, on television, and on the internet. Television and magazines have received most research attention as potential influences on adolescents' sexual development (Ward, 2003), but the internet is currently discussed as a potential impact (Greenfield, 2004; Lo \& Wei, 2005; Thornburgh \& Lin, 2002). Our definition of the three forms of sexual explicitness largely follows definitions that have been proven useful in content analyses (e.g., Kunkel et al., 2005). Sexually non-explicit content depicts sexual matters in indirect ways. It may contain nudity, but it is not the focus of the depiction; closeups of nude persons or body parts do not appear. Sexual intercourse may be implied or depicted, but the depiction typically remains discreet. Sexually non-explicit content can usually be found in mainstream movies or soaps. If the depiction of sexual intercourse involves nudity, it is not center-stage and does not show intimate touching. In sexually semi-explicit content, nudity is the center of attention. The depiction of sexual intercourse involves intimate touching and may suggest different forms of penetration, but they are not shown. Sexually semi-explicit content occurs, for example, in television series such as Sex Court or Sexcetera. Sexually explicit material shows genitals and sexual activities in unconcealed ways. Oral, vaginal, and anal penetration is clearly visible, typically shown in close-ups. Sexually explicit content is typically featured in "adult," "hardcore," or "XXX" productions.

\section{Sexualized Media Environment and Notions of Women as Sex Objects}

Regardless of whether sexual content is non-explicit, semiexplicit, or explicit, content analyses have consistently demonstrated that such content sexually objectifies women more often than men (for a review, see Ward, 2003). According to Fredrickson and Roberts (1997), the sexual objectification of women may be defined as the reduction of women to their sexual appeal in terms of their outer appearance and a focus on their body (parts). It also entails a strong concern with women's sexual activities as the main criterion of their attractiveness and the depiction of women as sexual playthings waiting to please men's sexual desires. In sexually non-explicit content as featured in prime-time television programming and music videos, a focus on women's bodies is more common than a focus on men's bodies (e.g., Grauerholz \& King, 1997; Seidman, 1992). For example, a content analysis of prime-time programming showed that, in $84 \%$ of the analyzed episodes, at least one incident of sexual harassment occurred. Thirty-two percent of all incidents of sexual harassment were verbal sexual comments that focused on women's bodies or body parts (Grauerholz \& King, 1997). An analyses of 182 music videos showed that $37 \%$ of women, as opposed to $4 \%$ of men, wore revealing clothing (Seidman, 1992).

In sexually semi-explicit men's magazines, scholars have also found a strong tendency to define women primarily by their looks and bodies, along with the depiction of women as sexually available (Krassas, Blauwkamp, \& Wesselink, 2001). In sexually semi-explicit movies, examples of female nudity outnumber males nudity in a ratio of 4:1 (Greenberg et al., 1993). Finally, sexually explicit material in videos, DVD's, magazines, and on the internet primarily treats women as sexual playthings and subordinates, whose bodies and genitals are the center of attention (e.g., Brosius, Weaver, \& Staab, 1993; Cowan, Lee, Levy, \& Snyder, 1988; Ertel, 1990). Cowan et al. (1988), for example, reported that $69 \%$ of sexually objectifying genitalia full-screen exposures were shots of women, and $31 \%$ were shots of men.

Despite the consistent findings of these content analyses, only a few studies have concerned the potential link between exposure to media coverage that sexually objectifies women and notions of women as sex objects. Ward (2002) presented correlational evidence that young adults who frequently watched television were more likely than young adults who watched television less often to believe that women are sex objects. In an experiment, Ward and Friedman (2006) were able to show that exposure to a television clip that objectified women increased notions of women as sex objects. Ward found a similar effect, yet only for female participants in the experimental group, as opposed to female subjects in the control group, but not for male subjects in the experimental group. Research is missing on the association between other media, such as print media or the internet, and views of women as sex objects. However, the findings of content analyses on the sexual objectification of women in sexually semi-explicit 
and sexually explicit content suggest that adolescents' exposure to a sexualized media environment may increase their notions of women as sex objects.

\section{Nature of the Relation Between Exposure to Sexual Content and Notions of Women as Sex Objects}

Although a positive association between exposure to a sexualized media environment and beliefs that women are sex objects seems plausible, the nature of this relationship still remains vague. More specifically, it is unclear to what extent notions of women as sex objects differ depending on the sexual explicitness of the content and its format (i.e., visual, such as pictures in magazines, or audio-visual, such as television shows or movies on the internet). Does exposure to sexual content of varied explicitness and across different formats add up in a (cumulative) association with beliefs that women are sex objects? Or is a hierarchical relation of the two constructs more likely, in which exposure to audio-visual and sexually explicit content is more strongly linked with notions of women as sex objects than exposure to visual and sexually non-explicit content?

We also know little about gender differences in exposure to sexual content of varied explicitness and beliefs that women are sex objects. Several studies have documented that the relation between exposure to sexual content and sexual beliefs may be conditional on adolescents' gender (for a review, see Ward, 2003). However, it is difficult to say whether the specific association between exposure to a sexualized media environment and beliefs that women are sex objects may be stronger for boys or girls.

Cumulative vs. hierarchical As mentioned above, the pervasiveness and increasing explicitness of sexual media content, along with its easy accessibility, lie at the heart of the concept of adolescents' sexualized media environment. This conceptualization suggests at least two patterns of how adolescents' exposure to a sexualized media environment may be related to beliefs that women are sex objects. We call the first pattern cumulative. By cumulative, we mean that adolescents' exposure to sexual content of varied explicitness and in different formats adds up in its association with beliefs that women are sex objects. The explicitness of sexual content and its visual or audiovisual format are less important than the fact that adolescents are exposed to sexual content repeatedly. As a result, regardless of the explicitness and the format of the content, more exposure to sexual content will be related to stronger beliefs that women are sex objects. In the present study, we focused on whether exposure to sexual content of varied explicitness and in different formats is significantly related to notions of women as sex objects. The strength with which each exposure is associated with notions of women as sex objects may specify the structure of the cumulative pattern, but was, at least in the present study, not of primary interest.

The cumulative pattern in the association between exposure to a sexualized media environment and sexual beliefs initially underlies the reasoning that points at media in general as a sexual socialization agent (e.g., L'Engle et al., 2006; Strasburger \& Donnerstein, 1999). At a methodological level, the cumulative pattern is implicitly assumed, for example, in the sexual media diet measure, with its combination of exposure to different sexual content in one measure (e.g., Brown et al., 2006). At a more practical level, the cumulative pattern in the relation between exposure and sexual beliefs informs, for instance, calls for more attention to media as psychosocial risk factors to adolescent health (e.g., Rich \& Bar-On, 2001).

Empirical studies based on the sexual media diet measure provide initial support for the cumulative pattern (Brown et al., 2006; L'Engle et al., 2006). However, the studies did not include exposure to sexually explicit material, and the researchers did not investigate the relative influence of the components of the sexual media diet measure as Brown et al. (2006) themselves pointed out. An extension of Brown and al.'s analysis thus requires that adolescents' exposure to different types of sexual explicitness and across different formats be analyzed separately in its potential association with beliefs that women are sexual objects. In a multiple regression analysis, a cumulative pattern would be indicated by significant relationships between notions of women as sex objects and exposure to non-explicit, semi-explicit, and explicit sexual content in both visual and audiovisual formats.

We call the second pattern of how adolescents' exposure to a sexualized media environment may be related to beliefs that women are sex objects the hierarchical pattern. The hierarchical pattern is implicitly assumed in the reasoning that considers sexually explicit content on the internet a more powerful sexual socialization agent than other forms of sexual content in traditional media (Donnerstein \& Smith, 2001; Paul, 2005; Thornburgh \& Lin, 2002). At a more practical level, the hierarchical pattern in the relation between exposure and sexual beliefs underlies requests as diverse as calling for special internet sex education in families and school (Greenfield, 2004) or advising parents how to protect their children from the internet (FreemanLongo, 2000). In contrast to the cumulative pattern, then, the hierarchical pattern does not entail that adolescents' exposure to sexual content across different types of explicitness and formats adds up in its association with beliefs that women are sex objects. Rather, sexual content relates hierarchically to notions of women as sex objects, depending on its sexual explicitness and its visual or audiovisual format. 
In terms of the explicitness of sexual content, a hierarchical pattern means that only sexually explicit content is eventually associated with notions of women as sex objects. Content analyses of sexually explicit content have suggested a sexual objectification of women through, for example, frequent fullscreen genitalia shots (Cowan et al., 1988), male ejaculation on the body, the face, or in the mouth of a woman (Brosius et al., 1993), and the depiction of women in a passive role (Ertel, 1990). At least in its frequency and intensity, the sexual objectification of women in sexually explicit content may thus be more distinct than sexual objectification of women in sexually non-explicit or sexually semi-explicit material. Moreover, a potential excitatory habituation with, and perhaps even desensitization to, less explicit sexual content (Zillmann \& Bryant, 1986) may result in a hierarchical pattern, in which only exposure to sexually explicit content is related to notions of women as sex objects.

In terms of the visual or audio-visual format of sexual content, a hierarchical pattern means that ultimately only audio-visual sexual content is linked with notions that women are sex objects. Content analyses have shown that, in sexually explicit audiovisual material, men sometimes speak to women in a derogatory, abusive way (e.g., Cowan et al., 1988, Ertel, 1990). In prime-time programming, sexual comments that focus on women's bodies and body parts occur frequently (Grauerholz \& King, 1997). As a result, the additional auditory channel in audiovisual material, and with it the possibility to express sexually objectifying verbal or acoustic messages (e.g., whistling), may lead to a stronger association between audiovisual sexual content and notions of women as sex objects than between exclusively visual sexual content and views of women as sex objects.

An adequate test of the hierarchical pattern in the association between exposure to a sexualized media environment and beliefs that women are sex objects requires that exposure to all three types of sexual explicitness be investigated both for visual and audiovisual formats. In the case of a hierarchical association pattern, a hierarchical multiple regression analysis would initially elicit significant associations between exposure to sexually non-explicit content and notions of women as sex objects. Subsequently, there would be significant associations for exposure to sexually semi-explicit content, but no longer for the consumption of sexually non-explicit content. However, once exposure to sexually explicit material is considered, only this type of exposure would have a significant relationship with beliefs that women are sex objects; the previously significant association between exposure to sexually semi-explicit content and these beliefs would disappear.

For each type of sexual explicitness, an initially significant effect of visual content would disappear once audiovisual content is taken into consideration. For example, whereas exposure to sexually non-explicit visual content (e.g., pictures in magazines) may at first be significantly related with notions of women as sex objects, this association may disappear when exposure to sexually non-explicit audio-visual content (e.g., on television) is considered. In a perfect hierarchical pattern, eventually only exposure to sexually explicit audio-visual content (e.g., in videos or in movies on the internet) would be linked with notions of women as sexual objects.

Although the characteristics of both a cumulative and a hierarchical pattern can be clearly described, current research evidence does not permit to specify which of the two is more likely to occur regarding the association between adolescents' exposure to a sexualized media environment and their notion of women as sex objects. Therefore, we formulated the following research question.

RQ 1: Can the relation between adolescents' exposure to a sexualized media environment and their notions of women as sex objects be better described as cumulative or hierarchical?

Gender-conditionality Based on a review of general gender differences in sexuality, Aubrey et al. (2003) have shown how important it is to take into account that men and women may react differently to sexual media content. The authors concluded from existing research that, on average and compared with women, men expect more sex from their partners; more often have sex for recreational, and to a lesser extent for relational, reasons; and hold more permissive sexual attitudes. Moreover, a sexual double standard still exists, according to which similar types of sexual behavior are considered more appropriate for men than for women. The belief that women are sex objects seems to be linked to several of these sexual dimensions in which men and women differ. From a theoretical perspective, general gender differences in sexuality may thus translate into specific gender differences in the relation between notions of women as sex objects and exposure to sexual content.

However, empirical research on gender differences in the influence of sexual content on notions of women as sex objects is somewhat inconclusive. In a study on the effects of non-explicit sexual television content, Ward (2002) found that female college students who had watched a sexually objectifying television clip agreed more strongly than female college students who had watched non-sexual content that women are sex objects. This difference, by contrast, did not occur for male college students who had been exposed to the same types of content. In a replication of the study with high school students, no gender differences emerged. Regardless of their gender, students who had watched sexually objectifying content supported the notion of women as sex objects more strongly than did students in the control condition (Ward \& Friedman, 2006). 
The inconclusiveness of research on gender differences in the response to sexual media content also pervades studies on attitudes that resemble the belief that women are sex objects. For example, the relationship between exposure to sexual content on television, such as in soaps and in music videos, has been found to be more strongly related to stereotypical sexual attitudes among female adolescents than among male adolescents (e.g., Strouse \& Buerkel-Rothfuss, 1995; Strouse, Goodwin, \& Roscoe, 1994). In contrast, exposure to magazine advertisements in which women were portrayed as sex objects led to a stronger acceptance of rape myths and sexual stereotypes among male college students than among their female peers (Lanis \& Covell, 1995; MacKay \& Covell, 1997). Finally, at least two studies suggest that it may depend on the genre and the type of sexual belief whether men or women are more affected by sexual content (Aubrey et al., 2003; Ward \& Rivadeneyra, 1999). As a result of the diversity of research findings, we could only conclude that adolescents' gender may moderate the relationship between their exposure to a sexualized media environment and notions of women as sex objects. However, we were not able to specify how this moderating influence might look and therefore formulated a research question:

RQ 2: To what extent does adolescents' gender moderate the relation between their exposure to a sexualized media environment and their notions of women as sex objects?

\section{Alternative Explanations}

Previous research on individual differences in beliefs about women as sex objects suggests that notions of women as sex objects have developmental, social, and cultural correlates. In the present study, with its focus on media exposure, these correlates may function as alternative explanations of why adolescents differ in notions of women as sex objects and should therefore be controlled for. For example, in terms of developmental variables, Ward (2002) has found that more sexually experienced adolescents held stronger notions of women as sex objects than did less sexually experienced adolescents (Ward, 2002). Regarding social variables, research has documented that men and boys are more likely than women and girls to endorse such beliefs (Ward, 2002; Ward \& Friedman, 2006). Concerning cultural variables, Ward also reported an influence of ethnicity on notions of women as sex objects. In the Netherlands, the Turkish and Moroccan adolescent minorities not only differ in their sexual behavior from the Dutch adolescent majority, but arguably also hold more traditional views of gender relations (Rutgers Nisso Group, 2005). As a result, non-Dutch adolescents may be more likely than Dutch adolescents to hold beliefs that women are sex objects.
The fact that developmental, social, and cultural factors are related to notions of women as sex objects dovetails with results from research on related sexual attitudes. Research on sexual attitudes suggests that it may be useful in addition to examine the following developmental, social, and cultural variables to test more compellingly the potential relationship between a sexualized media environment and beliefs about women as sex objects. In terms of extra developmental variables, adolescents' pubertal status and their relationship status may decrease notions of women as sex objects. In addition to age, pubertal status seems to be an informative indicator of adolescents' developmental stage. The consistently lower endorsement of beliefs that women are sex objects that Ward (2002) found among college students, as compared to high school students (Ward \& Friedman, 2006), provides some initial evidence for a potentially negative relation between pubertal status and this belief. The formation of a romantic relationship presents an important developmental step for adolescents (Miller, Christopherson, \& King, 1993) and may provide adolescents with more differentiated insights into what constitutes being a man or a woman. As a result, adolescents in a relationship may be less likely than adolescents who are single to see women as sex objects. Finally, adolescents' sexual orientation should be taken into consideration as a potentially confounding variable. The development of a sexual orientation presents an important task in adolescence, and gay and lesbian adolescents may differ from heterosexual adolescents in their views of women as sex objects.

In terms of additional social variables, adolescents' socio-economic background and their formal education may affect their beliefs about women as sex objects. Higher education and lower socio-economic status are associated with more support for women's emancipation (Glick, Lameiras, \& Castro, 2002; Townsend, 1993). This may also apply to the conceptually similar notion of women as sex objects. Finally, as a further cultural variable, adolescents' religiosity may reduce notions of women as sex objects. Religiosity generally diminishes sexualized world views (Le Gall, Mullet, \& Shafighi, 2002).

The present study has emphasized that adolescents' exposure to sexually explicit material, most notably on the internet, may be associated with notions of women as sex objects. In the present study, exposure refers to the purposeful consumption of such content. However, Greenfield (2004) and Mitchell, Finkelhor, and Wolak (2003) have emphasized that, on the internet, adolescents' may be inadvertently exposed to sexually explicit material, for example through pop-up windows or spam email. This unsolicited exposure to sexually explicit material may affect adolescents' notions of women as sex object. To make our test as rigorous as possible, we hence controlled for inadvertent exposure to sexually explicit on-line material. 
In summary, we included in our model, as developmental control variables, sexual experience, pubertal status, age, relationship status, and sexual orientation; as social control variables, gender, education, and socio-economic status; as cultural control variables, ethnicity and religiosity; and as additional exposure variable inadvertent exposure to sexually explicit on-line material.

\section{The Dutch Case}

The present study was conducted in the Netherlands, a country often cited for its progressive approach toward matters of adolescent sexuality (e.g., Unicef, 2001) and its liberal policy toward issues evolving around sexual media content (Drenth \& Slob, 1997). Furthermore, the Netherlands ranks among the top ten nations of the world according to the United Nations' gender-related development index and its gender empowerment measure (United Nations Development Programme, 2001). Finally, Dutch adolescents' media environment does not seem to differ significantly from the media environment of adolescents in other rich Western countries. Television programming in particular seems to be similar to US television programming, and many series and movies are imported from the US (Valkenburg \& Janssen, 1999). And, although the proportion of adolescents with home internet access is higher in the Netherlands than in most other countries, Dutch adolescents' actual use of the internet does not appear to differ from the internet use of adolescents in other countries (e.g., Valkenburg \& Peter, in press).

These characteristics of the Netherlands render it a country very well suited for the purposes of the present study. We were able to investigate, among sexually well-educated adolescents, exposure to a continuum of sexual content from various media, including the internet, without running the risk of producing results that are incompatible with findings from other rich Western countries. In addition, the relatively empowered role of Dutch women may present a strong counterforce against media depictions of women as sex objects. If we were to find a relationship between adolescents' exposure to a sexualized media environment and their notions of women as sex objects, we would not only have initial evidence of a phenomenon that may be soon detected in other countries, but we would also have a further indication of the media's important role in defining gender stereotypes.

\section{Method}

Participants and procedure

In March and April 2005, an on-line survey was conducted among 745 Dutch adolescents (48\% boys, 52\% girls) between 13 and 18 years of age $(M=15.5, S D=1.69)$. Ninety-two percent of the respondents were Dutch, the remaining $8 \%$ belonged to other ethnic groups. For the study of sensitive issues, on-line surveys or, more generally, computer-mediated surveys have generally proven superior to other modes of interviewing (e.g., Mustanski, 2001). Respondents were recruited from an existing online panel managed by Intomart GfK, an established audience and media research institute in the Netherlands. Sampling and fieldwork were done by Intomart GfK. The institute had sampled the respondents in all parts of the Netherlands, partly through random telephone interviews, partly through respondents' social networks, and requested from each respondent informed consent and, for the minors, parental consent before the adolescents took part in research. The response rate was $60 \%$. Analyses showed that the gender, age, and formal education of our respondents did not deviate from official statistics. Prior to the implementation of the survey, institutional approval was obtained from our university.

Adolescents were notified that the study would be about sexuality and the internet and, if they wished, they could stop participation at any time. We took several steps to improve the confidentiality, anonymity, and privacy of the response process (Mustanski, 2001). On the introduction screen of the on-line questionnaire, we emphasized that the answers would be analyzed only by us, the principal investigators. Moreover, respondents were asked to make certain that they filled in the questionnaire in private. Finally, we assured the respondents that their answers would remain anonymous. That is, we explained explicitly that there was no possibility for the principal investigators to identify who had filled in the questionnaire and that, on the other hand, Intomart GfK could not see what the respondents answered. Intomart GfK did not link respondents' answers in our questionnaire to their names and contact information, and only provided us with the background variables plus the answers to our questionnaire. This procedure has proven successful in various other studies on sensitive issues and ensures the protection of respondents' anonymity. Completing the questionnaire took about $15 \mathrm{~min}$.

For the regression analyses presented in this article, we had complete data from 674 of the 745 respondents who had started the questionnaire. Further analyses indicated that, in terms of age, gender, ethnicity, and formal education, the 674 respondents for whom we had complete data did not meaningfully deviate from those respondents for whom we lacked complete data.

Measures

Exposure to sexually non-explicit content in magazines We operationalized this concept with adolescents' exposure to 
three Dutch magazines that typically include some sexual content (e.g., Actueel). These magazines have a recreational orientation. They report about sports, crime, and erotica, typically in a slightly sensationalist way. Adolescents were asked how many issues of a particular magazine they usually read; response categories ranging from 1 (none) to 7 (all issues). The factor structure was uni-dimensional (explained variance $80 \%$ ), and resulted in a Cronbach's Alpha of $.87(M=1.27, S D=.82)$.

Exposure to sexually non-explicit content on television We operationalized this measure by drawing on a question that asked adolescents to what extent they were interested in various types of television programming. Based partly on results from content analyses (e.g., Kunkel et al., 2005; Pardun et al., 2005; for a review, see Ward, 2003), we included television genres that present at least some sexually non-explicit content: soap operas (e.g., Good Times, Bad Times), music shows (e.g., on MTV), comedy series (e.g., Friends, Sex in the City), romantic movies (e.g., When Harry Met Sally), romantic shows (e.g., All You Need Is Love), and action series (e.g., 24, JAG). Response categories ranged from 1 (not interested at all) to 4 (very much interested). The factor structure of the scale was unidimensional (explained variance 42\%), Cronbach's alpha was .72 $(M=2.82, S D=.69)$.

Exposure to sexually semi-explicit content in magazines This measure was operationalized with two items - adolescents' exposure to Playboy and Penthouse. Adolescents were asked to indicate how many issues of Playboy and Penthouse they usually read, and the response categories ranged from 1 (none) to 7 (all issues). The two items correlated at .80 , Cronbach's alpha was $.89(M=1.16$, $S D=.71)$.

Exposure to sexually semi-explicit content on television This measure was operationalized with adolescents' frequency of exposure to three sexually semi-explicit television programs (Sexcetera, Sex Court, Latin Lover). The respondents were asked how often, in the past year, they had on average watched the three television programs. Response categories ranged from 1 (never) to 5 (several times a week). When the three items were entered into a factor analysis, they formed a unidimensional scale (explained variance 78\%). Cronbach's alpha was $.85(M=$ $1.28, S D=.59$ ).

To test whether exposure to sexually semi-explicit content on television was also empirically distinguishable from exposure to sexually non-explicit content on television, we z-transformed the items used for the two scales and subjected them to a factor analysis with varimax rotation. The resulting two factors exactly mirrored the operationalization of the two scales, which indicates that the two constructs are empirically independent.

Exposure to sexually explicit material in magazines Adolescents were asked to indicate how often they had, on average, read erotic magazines in the past year. Response categories ranged from 1 (never) to 5 (several times a week) $(M=1.35, S D=.76)$. In Dutch, the term erotic magazines is often used as a euphemism for sexually explicit Dutch magazines, which present vaginal, oral, and anal sex in unconcealed, uncensored ways. To test whether exposure to sexually explicit magazines (i.e., erotic magazines) was different from what we defined as exposure to sexually semi-explicit magazines (i.e., Playboy and Penthouse), we correlated the three items. Exposure to erotic magazines was only moderately correlated with exposure to Playboy, $r$ $=.24, p<.001$, and Penthouse, $r=.15, p<.001$. The relatively low correlations support the expected difference between exposure to sexually semi-explicit material (as displayed in the Dutch versions of Playboy and Penthouse) and the more explicit material available in Dutch erotic magazines.

Exposure to sexually explicit material on video/DVD The respondents were asked how often, in the past year, they had, on average, watched a pornographic movie. Response categories ranged again from 1 (never) to 5 (several times a week $)(M=1.43, S D=.90)$.

Exposure to sexually explicit pictures on the internet Adolescents were asked how often, in the past 6 months, they had, on average, looked at on-line pictures in which people are having sex. The response categories were 1 (never), 2 (less than once a month), 3 (1-3 times a month), 4 (once a week), 5 (several times a week), and 6 (every day), $(M=$ $1.87, S D=1.29$ ).

Exposure to sexually explicit movies on the internet We asked adolescents how often, in the past 6 months, they had, on average, watched on-line movies or movie clips in which people are having sex. The response categories were the same as for exposure to sexually explicit pictures on the internet $(M=1.82, S D=1.28)$.

Pre-tests revealed that adolescents did not need more elaborate explanations as to the content of the two items that we used to measure exposure to sexually explicit online pictures and movies. The respondents were aware that the two items were about sexually explicit content and their purposeful exposure to them.

Women as sex objects We largely followed an operationalization by Ward (2002), but adjusted it slightly for the use among Dutch adolescents. Furthermore, we replaced two 
items of Ward's original scale (i.e., whistling at shapely women, attractive women give men prestige) with two items that more strongly refer to sex (i.e., "Unconsciously, girls always want to be persuaded to have sex" and "Sexually active girls are more attractive partners"). Response categories ranged from 1 (disagree completely) to 5 (agree completely). In a subsequent factor analysis with varimax rotation, the three items of Ward's scale that dealt with face and body care and the importance of women's appearance to attract men loaded on a separate factor. As a result, we eventually measured the concept of women as sex objects with the remaining three items from Ward's scale (i.e., "An attractive woman should expect sexual advances;" "It bothers me when a man is interested in a women only if she is pretty;" "There is nothing wrong with men being primarily interested in a woman's body") plus the two items we had added. These five items formed a unidimensional scale (explained variance $50 \%$ ), with a Cronbach's alpha of .75 $(M=2.81, S D=.74)$.

Age and gender The measurement of age and gender was straightforward. Boys were coded with 0 , girls with 1 .

Ethnicity We operationalized respondents' race/ethnicity as a dichotomy where 0 meant Non-Dutch, and 1 meant Dutch.

Sexual experience We operationalized sexual experience with three items: mutual masturbation, oral sex, and coital sex. Pre-tests revealed that adolescents had no problems understanding the terms. Respondents were asked whether they had performed one or more of the three behaviors. To avoid problems with the log-transformation of the resulting scale, experience with a particular sexual behavior was coded as 2; lacking experience with a particular behavior was coded as 1 . The three items loaded on one factor (explained variance 81\%). We first summed these items and then divided them by the number of items to form a scale. The resulting alpha was $.88(M=1.30, S D=.41)$.

Education Education was measured on a 5-point scale that represented the different educational levels at which Dutch adolescents can be $(M=2.75, S D=1.22)$. The response categories were 1 (Elementary education, lower vocational education), 2 (Lower general secondary education), 3 (Intermediate vocational education), 4 (Higher general secondary education, pre-university education) and 5 (Higher vocational education, university). It should be noted that, in the Netherlands, adolescents of the same age may have different formal levels of education. This also shows in a modest correlation of $r=.23$ between formal education and age.
Socio-economic status Adolescents' socio-economic resources were operationalized as a combination of two measures: the profession and the educational level of the family's primary breadwinner (i.e., the person that earns most of the money in a family). For example, if the family's breadwinner has a low formal education and does unskilled work, a low socio-economic status results. In contrast, somebody with a university degree and in a leading professional position would be assigned a high socioeconomic status. The two measures were combined so that a 5-point scale resulted. The anchors of the resulting scale were 1 (low socio-economic status) and 5 (high socioeconomic status) $(M=2.97, S D=1.28)$.

Religiosity Whether adolescents are religious was measured with the item "I am religious." Response categories ranged from 1 (does not apply at all) to 5 (applies completely) (M $=2.23, S D=1.33)$.

Pubertal status Pubertal status was operationalized with the Pubertal Status Scale developed by Petersen, Crockett, Richards, and Boxer (1988). The scale contains five items for boys - body hair, voice change, skin change, growth spurt, and facial hair - and five for girls - body hair, breast change, skin change, growth spurt, and menstruation. We removed the skin change item because Petersen et al. noted that it was the least reliable and least valid of the various items. Adolescents could indicate on a 4-point scale that ranged from 1 (has not started yet) to 4 (has already finished) whether each bodily change had already begun or had already finished. For validity reasons, we did not provide girls with the response category has already finished for the menstruation item. The internal consistency of the scale was .89 for boys $(M=2.91, S D=.83)$ and .82 for girls $(M=3.19, S D=.56)$.

Relationship status Adolescents' relationship status was measured with the question "Are you currently in a romantic relationship?" Adolescents who were single were coded $0(67.9 \%)$; adolescents who had a relationship were coded $1(32.1 \%)$.

Sexual orientation Adolescents were asked whether they were gay/lesbian, bisexual, or heterosexual. In the present study, we included sexual orientation only to account for potential differences in heterosexual and non-heterosexual adolescents in their notions of women as sex objects. We therefore dichotomized the variable into non-heterosexual adolescents (coded 0,6.8\%) and heterosexual adolescents (coded 1, $93.2 \%$ ).

Inadvertent exposure to sexually explicit material on the internet We asked adolescents how often, on average, they 
had by chance encountered explicit sexual content on the internet in the last 6 months. The sexual content we referred to was (a) pictures with clearly exposed genitals; (b) movies with clearly exposed genitals; (c) pictures in which people are having sex; (d) movies in which people are having sex; (e) erotic contact sites. On erotic contact sites, people can get in touch with other people for sexual purposes, for example by posting visually and/or textually sexually explicit profiles, which may also appear in a context of sexually explicit advertising or links. The response categories were 1 (never), 2 (less than once a month), 3 (1-3 times a month), 4 (once a week), 5 (several times a week), and 6 (every day). The items loaded on one factor (explained variance $67 \%$ ), and resulted in a Cronbach's alpha of .87 $(M=2.10, S D=1.11)$.

\section{Data analysis}

We conducted hierarchical multiple regression analyses to test our research questions. Multiple regression analysis assumes that the variables have normal distributions, but sexual measures are typically positively skewed. Prior to the multiple regression analysis, we conducted ShapiroWilk tests for normality to determine whether the metric variables were normally distributed. As a result of the test, we had to log-transform the measures of religiosity, pubertal status, sexual experience, and all exposure measures. Because some of our measures might be strongly correlated, we checked whether there was evidence of multicollinearity between the variables. This was not the case; all variance inflation factors were clearly below the critical value of 4.0. The Cook-Weisberg test confirmed that our model met the assumption of homoskedasticity. For the investigation of the interaction terms between adolescents' gender and their exposure to various sexual content, we centered the exposure variables around their means to avoid multicollinearity problems (Aiken \& West, 1991).

\section{Results}

Table 1 presents the zero-order correlations between the core variables of the study, the various forms of exposure to sexual content and the belief that women are sex objects. With the exception of exposure to sexually non-explicit content in magazines and on television, all other exposure forms were significantly positively associated with beliefs that women are sex objects. Two patterns in the associations between the different forms of exposure seem noteworthy. First, exposure to sexually non-explicit content on television was not at all or negatively associated with exposure to sexually semi-explicit or sexually explicit content. Second, exposure to sexually semi-explicit content on television and exposure to sexually explicit content in magazines, in films/DVD's, and on the internet were strongly interrelated. Overall, Table 1 suggests an exposure pattern along the lines of sexual explicitness. By and large, adolescents seem to prefer either sexually non-explicit content or sexually explicit content; exposure to sexually semi-explicit content, particularly on television, is more strongly related with exposure to sexually explicit content than with exposure to sexually non-explicit content.

Adolescents' gender predicted their exposure to the various forms of sexual content and their beliefs that women are sex objects. Exposure to sexually non-explicit magazines did not differ for girls and boys $\left(M_{\text {Girls }}=1.24\right.$, $\left.S D_{\text {Girls }}=.78, M_{\text {Boys }}=1.29, S D_{\text {Boys }}=.86\right), t(742)=.86$, n.s. But girls watched sexually non-explicit content on television more often than boys did $\left(M_{\text {Girls }}=3.12, S D_{\text {Girls }}=.58\right.$, $\left.M_{\text {Boys }}=2.50, S D_{\text {Boys }}=.65\right), t(724)=-13.69, p<.001$. Compared with girls, boys consumed significantly more often sexually semi-explicit content in magazines $\left(M_{\text {Girls }}=1.05\right.$, $\left.S D_{\text {Girls }}=.37\right), M_{\text {Boys }}=1.29, S D_{\text {Boys }}=.94, t \quad(742)=4.68$, $p<.001$, sexually semi-explicit content on television $\left(M_{\text {Girls }}=1.13, S D_{\text {Girls }}=.38, M_{\text {Boys }}=1.43, S D_{\text {Boys }}=.72\right), t$ $(732)=7.21, p<.001$, sexually explicit content in magazines $\left(M_{\text {Girls }}=1.17, S D_{\text {Girls }}=.54, M_{\text {Boys }}=1.53, S D_{\text {Boys }}=.91\right), t$ $(732)=6.64, p<.001$, sexually explicit content on film/ DVD $\left(M_{\text {Girls }}=1.13, S D_{\text {Girls }}=.52, M_{\text {Boys }}=1.74, S D_{\text {Boys }}=\right.$ $1.09), t(732)=9.80, p<.001$, sexually explicit pictures on the internet $\left(M_{\text {Girls }}=1.40, S D_{\text {Girls }}=.86, M_{\text {Boys }}=2.38\right.$, $\left.S D_{\text {Boys }}=1.47\right), t(727)=11.12, p<.001$, and sexually explicit movies on the internet $\left(M_{\text {Girls }}=1.37, S D_{\text {Girls }}=.83, M_{\text {Boys }}=\right.$ 2.30, $\left.S D_{\text {Boys }}=1.49\right), t(727)=10.49, p<.001$. In contrast to girls, boys held significantly more often notions that women are sex objects $\left(M_{\text {Girls }}=2.58, S D_{\text {Girls }}=.67, M_{\text {Boys }}=\right.$ 3.01, $\left.S D_{\text {Boys }}=.73\right), t(727)=12.11, p<.001$.

\section{Nature of the relation}

Our two research questions investigated two aspects of the association between exposure to sexual content of varied explicitness and across visual and audio-visual formats: first, whether the association is cumulative or hierarchical, and second, to what extent the relation depends on adolescents' gender.

Cumulative vs. hierarchical To test the cumulative or hierarchical nature of the association, we conducted hierarchical multiple regressions (see Table 2). We began the hierarchical regression analysis with a base model that included alternative explanations of beliefs that women are sex objects. Next, we successively entered the various exposure measures, starting with exposure to sexually nonexplicit sexual content (Models 1 and 2), continuing with 
Table 1 Zero-order correlations between exposure measures and notions of women as sex objects.

\begin{tabular}{|c|c|c|c|c|c|c|c|c|}
\hline & Women as sex object & (1) & (2) & (3) & (4) & $(5)$ & (6) & (7) \\
\hline (1) Non-explicit magazines (ln) & -.04 & & & & & & & \\
\hline (2) Non-explicit television (ln) & $-.09^{\mathrm{a}}$ & $.09^{\mathrm{a}}$ & & & & & & \\
\hline (3) Semi-explicit magazines (ln) & $.13^{\mathrm{c}}$ & $.36^{\mathrm{c}}$ & .03 & & & & & \\
\hline (4) Semi-explicit television (ln) & $.27^{\mathrm{c}}$ & $.10^{\mathrm{b}}$ & -.04 & $.22^{\mathrm{c}}$ & & & & \\
\hline (5) Explicit magazines (ln) & $.23^{\mathrm{c}}$ & $.23^{\mathrm{c}}$ & $-.09^{\mathrm{a}}$ & $.28^{\mathrm{c}}$ & $.49^{\mathrm{c}}$ & & & \\
\hline (6) Explicit pictures internet (ln) & $.30^{\mathrm{c}}$ & .06 & $-.11^{\mathrm{b}}$ & $.22^{\mathrm{c}}$ & $.45^{\mathrm{c}}$ & $.46^{\mathrm{c}}$ & & \\
\hline (7) Explicit video/DVD (ln) & $.30^{\mathrm{c}}$ & .04 & $-.12^{\mathrm{b}}$ & $.23^{\mathrm{c}}$ & $.62^{\mathrm{c}}$ & $.53^{\mathrm{c}}$ & $.55^{\mathrm{c}}$ & \\
\hline (8) Explicit movies internet (ln) & $.31^{\mathrm{c}}$ & .05 & -.07 & $.22^{\mathrm{c}}$ & $.49^{\mathrm{c}}$ & $.44^{\mathrm{c}}$ & $.72^{\mathrm{c}}$ & $.61^{\mathrm{c}}$ \\
\hline
\end{tabular}

Note. ${ }^{\mathrm{a}} p<.05,{ }^{\mathrm{b}} p<.01,{ }^{\mathrm{c}} p<.001$ (two-tailed); (ln) $=\log$-transformed.

exposure to sexually semi-explicit content (Models 3 and 4) and ending with exposure to sexually explicit material (Models 5 and 6). At each of these three levels of sexual explicitness, we entered exposure to sexual content in a visual format (i.e., pictures in magazines or on the internet) before exposure to sexual content in an audiovisual format (i.e., television, video, or movies on the internet). In Models 5 and 6 , we separated exposure to sexually explicit content

Table 2 Exposure to a sexualized media environment and notions of women as sex objects.

\begin{tabular}{|c|c|c|c|c|c|c|c|}
\hline \multirow[t]{2}{*}{$(\mathrm{N}=674)$} & \multicolumn{7}{|l|}{ Models } \\
\hline & Base & 1 & 2 & 3 & 4 & 5 & 6 \\
\hline \multicolumn{8}{|l|}{ Control variables } \\
\hline Girls & $-.30^{\mathrm{c}}$ & $-.30^{\mathrm{c}}$ & $-.32^{\mathrm{c}}$ & $-.30^{\mathrm{c}}$ & $-.26^{\mathrm{c}}$ & $-.23^{\mathrm{c}}$ & $-.20^{\mathrm{c}}$ \\
\hline Age & $-.11^{\mathrm{a}}$ & -.11 & -.10 & -.10 & -.07 & -.07 & -.07 \\
\hline Education & .02 & .02 & .02 & .01 & .00 & .01 & .00 \\
\hline Socio-economic status & -.01 & -.00 & -.00 & -.01 & -.02 & -.02 & -.01 \\
\hline Dutch ethnicity & .00 & .00 & .00 & -.00 & -.01 & -.00 & -.00 \\
\hline Religiosity (ln) & .03 & .03 & .02 & .02 & .02 & .02 & .02 \\
\hline In relationship & -.00 & -.00 & .00 & .01 & .02 & .02 & .01 \\
\hline Pubertal status (ln) & -.02 & -.02 & -.03 & -.02 & -.04 & -.04 & -.05 \\
\hline Sexual experience $(\ln )$ & .07 & .07 & .07 & .06 & .02 & .02 & .01 \\
\hline Heterosexual orientation & .01 & .01 & .01 & .01 & .04 & .03 & .03 \\
\hline Inadvertent exposure explicit internet $(\ln )$ & $.11^{\mathrm{b}}$ & $.11^{\mathrm{b}}$ & $.11^{\mathrm{b}}$ & $.10^{\mathrm{a}}$ & .06 & -.02 & -.04 \\
\hline \multicolumn{8}{|l|}{ Sexual exposure variables } \\
\hline Non-explicit magazines (ln) & & -.04 & -.04 & -.07 & -.07 & -.08 & -.06 \\
\hline$\Delta \mathrm{R}^{2}$ & & .001 & & & & & \\
\hline Non-explicit television (ln) & & & .04 & .04 & .02 & .03 & .03 \\
\hline$\Delta \mathrm{R}^{2}$ & & & .002 & & & & \\
\hline Semi-explicit magazines (ln) & & & & $.08^{\mathrm{a}}$ & .06 & .05 & .04 \\
\hline$\Delta \mathrm{R}^{2}$ & & & & $.006^{\mathrm{a}}$ & & & \\
\hline Semi-explicit television $(\ln )$ & & & & & $.18^{\mathrm{c}}$ & $.13^{\mathrm{b}}$ & .08 \\
\hline$\Delta \mathrm{R}^{2}$ & & & & & $.024^{\mathrm{c}}$ & & \\
\hline Explicit magazines $(\ln )$ & & & & & & .06 & .04 \\
\hline Explicit pictures internet $(\ln )$ & & & & & & $.14^{\mathrm{b}}$ & .06 \\
\hline$\Delta \mathrm{R}^{2}$ & & & & & & $.014^{\mathrm{b}}$ & \\
\hline Explicit video/DVD (ln) & & & & & & & .10 \\
\hline Explicit movies internet $(\ln )$ & & & & & & & $.11^{\mathrm{a}}$ \\
\hline$\Delta \mathrm{R}^{2}$ & & & & & & & $.011^{\mathrm{b}}$ \\
\hline Total $\mathrm{R}^{2}$ & $.124^{\mathrm{c}}$ & $.125^{\mathrm{c}}$ & $.127^{\mathrm{c}}$ & $.133^{\mathrm{c}}$ & $.157^{\mathrm{c}}$ & $.171^{\mathrm{c}}$ & $.182^{\mathrm{c}}$ \\
\hline Total Adj. $\mathrm{R}^{2}$ & .110 & .110 & .110 & .114 & .138 & .149 & .158 \\
\hline
\end{tabular}

Note. ${ }^{\mathrm{a}} p<.05,{ }^{\mathrm{b}} p<.01,{ }^{\mathrm{c}} p<.001$ ( $t$-test, $F$-test, two-tailed); (ln)=log-transformed; cell entries are standardized regression coefficients. 
on the internet from exposure to sexually explicit material in magazines (Model 5) and on video/DVD (Model 6) to test whether on-line exposure to such material makes a difference.

The base model in the second column of Table 2 shows that male and younger adolescents believed more strongly than female and older adolescents that women are sex objects. Further, more frequent inadvertent exposure to sexually explicit material on the internet was related to stronger notions that women are sex objects. None of the other control variables affected adolescents' notion that women are sex objects. In Model 1, the addition of adolescents' exposure to sexually non-explicit content in magazines neither resulted in a significant association with notions of women as sex objects nor in a significant improvement of the explained variance, $\Delta R^{2}=.001$, n.s. Similar results as in Model 1 emerged in Model 2 when we included exposure to sexually non-explicit content on television, $\Delta R^{2}=.002$, n.s.

However, exposure to sexually semi-explicit content in magazines, as entered in Model 3, was significantly positively related with beliefs that women are sex objects and significantly increased the explained variance of the model, $\Delta R^{2}=.006, \Delta F(1,659)=4.38, p<.05$. An even bigger improvement in the explained variance of the model resulted when we added exposure to sexually semi-explicit content on television, as model 4 shows, $\Delta R^{2}=.024, \Delta F(1$, $658)=18.83, p<.001$. Exposure to sexually semi-explicit content on television had a strong positive relation with notions of women as sex objects, $\beta=.18, p<.001$. In line with a hierarchical pattern in the relation between exposure to a sexualized media environment and notions of women as sex objects, the previously significant association between exposure to sexually semi-explicit content in magazines dropped below conventional significance levels, $\beta=.06$, n.s., when exposure to sexually semi-explicit content on television was included in the model.

Model 5 indicates that adolescents' exposure to sexually explicit pictures on the internet was significantly positively associated with the belief that women are sex objects, $\beta=.14, p<.01$. This was not the case for exposure to sexually explicit magazines, $\beta=.06$, n.s. Inclusion of these two variables in the model significantly increased the explained variance, $\Delta R^{2}=.014, \Delta F(2,656)=5.38, p<.01$. The relation between exposure to sexually semi-explicit content on television and the dependent variable became weaker, but was still significant. Finally, in Model 6, we included adolescents' exposure both to sexually explicit material on video/DVD and to sexually explicit movies on the internet. Exposure to sexually explicit movies on the internet was significantly related with the notion that women are sex objects, $\beta=.11, p<.05$, whereas exposure to sexually explicit material on video/DVD was not, $\beta=.10$, n.s. The explained variance of the model significantly increased when the two variables were included in the model, $\Delta R^{2}=.011$, $\Delta F(2,654)=4.54, p<.01$. The previously significant relation between exposure to sexually explicit pictures on the internet and the dependent variable disappeared, $\beta=.06$, n.s. The association between exposure to sexually semi-explicit content on television and the dependent variable was also no longer significant, $\beta=.08$, n.s.

To sum up, we found, in line with our expectation, that adolescents' exposure to sexual media content was linked with stronger beliefs that women are sexual objects. More specifically and in response to our first research question, the results showed that the nature of this association can be described best as hierarchical.

Gender conditionality If the relation between exposure to a sexualized media environment and the notion of women as sex objects is moderated by adolescents' gender, we would expect significant interaction effects between gender and one or more of the exposure measures. This was not the case. We did not find any significant interaction effects between the eight exposure measures and their association with beliefs that women are sex objects. Likewise, adding the eight interaction terms to the model did not significantly increase the explained variance of the model, $\Delta R^{2}=.011$, $\Delta F(8,646)=1.12$, n.s. In response to the second research question, then, our analyses indicated that the hierarchical pattern in the association of adolescents' exposure to a sexualized media environment and their notion of women as sex objects applied equally to boys and girls.

\section{Discussion}

Similar to previous research (Ward, 2002; Ward \& Friedman, 2006), our study has shown that adolescents' exposure to a sexualized media environment is associated with stronger notions of women as sex objects. As requested by Brown et al. (2006), we specifically studied how exposure to sexual content of varied explicitness and in different formats is linked with beliefs that women are sex objects. We found that the relation between exposure to a sexualized media environment and notions of women as sex objects can largely be described as hierarchical: Starting with adolescents' exposure to sexually semi-explicit content, the statistical significance of the association with notions of women as sex objects moved from semi-explicit content to more explicit sexual content. Exposure to sexual content in visual formats (i.e., pictures in magazines and on the Internet) generally lost its significant relation with notions of women as sex objects when sexual content in audiovisual formats were considered (i.e., television and movies on the Internet). Exposure to sexually explicit 
movies on the internet was the only exposure measure significantly related to beliefs that women are sex objects in the final regression model, in which exposure to other forms of sexual content was controlled. This pattern applied to both girls and boys.

Adolescents' exposure to sexual media content and their sexual beliefs

In line with previous research, most notably studies based on adolescents' sexual media diet (Brown et al., 2006; L'Engle et al., 2006; Pardun et al., 2005), this investigation focused on the entity of adolescents' exposure to sexual media content in order to better understand their sexual beliefs. In contrast to previous research, however, we did not find a cumulative, but a hierarchical pattern in the relation between adolescents' notions of women as sex objects and their exposure to sexual content of varied explicitness in visual and audiovisual formats. Our specific result by no means implies that the cumulative pattern is generally invalid. Pardun et al. (2005) analyzed separately the influence of adolescents' exposure to television, movies, music, and magazines on intentions to have sex, and they found a cumulative pattern. This initially suggests that the occurrence of a cumulative or hierarchical pattern might depend on the type of sexual variable studied. Sexual attitudes may be differently related with exposure to a sexualized media environment than are sexual intentions or sexual behaviors.

Further, the emergence of a cumulative or hierarchical pattern may hinge on which forms of exposure to sexual media content are studied. Therefore, future studies should also include exposure to sexual content in video games and music videos. In addition, it may be interesting to see whether exposure to sexually non-explicit and sexually semi-explicit content on the internet changes the pattern of results obtained in our study. Finally, researchers should also consider sexual stories of varied explicitness to test rigorously whether the hierarchical pattern that we found in terms of visual and audiovisual formats holds in the presence of written formats. The more encompassing the inventory of sexual content which adolescents currently use becomes, the better we will be able to understand whether adolescents' exposure to sexual content is cumulatively or hierarchically related to their sexual beliefs.

Exposure to sexually explicit movies on the internet was crucial for the hierarchical pattern in the relationship between adolescents' exposure to a sexualized media environment and their notions of women as sex objects. This finding confirms Brown et al.'s (2006) presumption that sexually explicit content, particularly on the internet and in an audio-visual format, plays an important role for the formation of adolescents' sexual beliefs. Although adolescents are not supposed to consume sexually explicit material, they do (Lo \& Wei, 2005; Peter \& Valkenburg, 2006) - and their consumption resonates with whether they believe that women are sex objects. The internet plays a key role in providing adolescents with access to sexually explicit material. This also showed in our finding that, when pitted against each other, only exposure to sexually explicit movies on the internet was significantly related to notions of women as sex objects, whereas exposure to sexually explicit movies on video or DVD was not. Although the internet is itself only part of a generally sexualized media environment, it seems to largely define this environment in terms of its sexual explicitness. Sexualization of adolescents' media environment consequently does not only mean that adolescents get more of the same sexually non-explicit content in different media; it also means that they get more sexually explicit content, and this happens predominantly on the internet. Therefore, it seems paramount that exposure to sexually explicit material, most notably on the internet and in an audio-visual format, receive more attention in future research.

Unlike in many earlier studies, we did not find an association between adolescents' exposure to sexually nonexplicit content on television or magazines and their belief that women are sex objects. The hierarchical relation between exposure to sexual content and notions of women as sex objects only emerged with adolescents' exposure to sexually semi-explicit content in magazines and on television. Two methodological and one conceptual explanation of this finding are possible. First, we operationalized exposure to sexually non-explicit content on television with the proxy variable of adolescents' interest in various television genres with sexual content. Although correlations with other exposure measures did not suggest any dubious patterns, a more valid operationalization of exposure to sexually non-explicit television content might have produced different findings. Second, it may be that exposure to sexually non-explicit content on television must be measured more specifically than it was done in our study. We chose, in line with previous studies, categories that typically include sexual issues (e.g., soaps, music shows, and movies). However, it may be that exposure to sexually non-explicit content on television needs to be captured with exposure to specific soaps or specific genres of music videos that have been identified as particularly sexualized (e.g., gangsta rap music clips in which men are glorified as "pimps" and women are treated as "bitches").

A third, more conceptual explanation of our finding may refer to desensitization processes among adolescents. Given the degree of explicitness in sexual content currently available to adolescents, more traditional, sexually nonexplicit content may have become so normal for adolescents that they hardly notice the sexual messages of the content. Only when a certain level of sexual explicitness is 
displayed in sexual content do the ramifications of exposure to this content begin to show, for example, in the sexual objectification of women. Zillmann and Bryant (1986, 1988) have described such desensitization effects for men repeatedly exposed to sexually explicit material, but they are also conceivable for adolescents exposed to sexual content in the mainstream media. This adds the dimension of contextsensitivity to the concept of a sexualized media environment (Peter, 2004). The same sexual media content may not be equally related to sexual beliefs; the strength of the association may rather depend on the extent to which the media environment is sexualized. Depending on the extent of sexualization of the media environment, sexual media content of different types of explicitness may be related to sexual beliefs. Given that the majority of research is USbased and our study was done in the Netherlands, crossnational comparative researchers may find it an interesting task to test the context sensitivity of the association between exposure to sexual media content and sexual beliefs.

\section{Women as sex objects}

The present study contributes to a small but coherent body of research that shows that the relatively homogeneous media depiction of women as sex objects is linked with adolescents' notions of women as sex objects (Ward, 2002; Ward \& Friedman, 2006). However, our study extends previous research in that it points to the importance of adolescents' exposure to sexually explicit material, most notably on the internet and in an audio-visual format. Our findings are in line with two different strands of research. First, the fact that we found sexually explicit on-line movies to be related with notions of women as sex objects concurs with content analyses that have demonstrated that women are objectified in sexually explicit material (e.g., Brosius et al., 1993; Cowan et al., 1988; Ertel, 1990). This objectification may partly result from men's derogatory sexual comments about women (Cowan et al., 1988; Ertel, 1990). Second, our result that exposure to audiovisual sexually explicit content on the internet rather than exposure to such content on video or DVD was associated with beliefs that women are sex objects tentatively supports researchers who have argued that, due to its easy accessibility, sexual content on the internet may play a crucial role in the sexual socialization of adolescents (Donnerstein \& Smith, 2001; Greenfield, 2004; Thornburgh \& Lin, 2002).

With its cross-sectional design, the present study was not able to identify a clear causal direction between exposure to a sexualized media environment and beliefs that women are sex objects. Exposure to sexual media content may boost adolescents' beliefs that women are sex objects. But, based on our data, it is equally likely that adolescents who believe that women are sex objects feel especially attracted by sexually explicit material and consequently turn to this content frequently. This puzzle can only be solved with longitudinal designs, given the ethical problems of experimental research in studies on sexually explicit material with minors. Regardless of whether exposure to a sexualized media environment affects beliefs that women are sex objects or vice versa, the association between the two is already of great social relevance. In many Western countries, the past 30 years have seen attempts to achieve sexual relations that are characterized by gender equality and mutual understanding and respect. In the same vein, issues such as the sexual double standard, gender stereotypes, and the sexual exploitation and abuse of women have entered public discourse. If we now see that - among both female and male adolescents - notions of women as sex objects are linked with exposure especially to sexually explicit material, we may possibly witness a mediarelated change in gender and sexual relations. The concepts and results presented here may present a first call to further investigate this issue.

Acknowledgments The authors would like to thank two anonymous reviewers for their insightful comments on an earlier draft of this article. The study was funded by grants from the Netherlands Organisation for Scientific Research (NWO) to both the first and the second author.

\section{References}

Aiken, L. S., \& West, S. G. (1991). Multiple regression: Testing and interpreting interactions. Newbury Park, CA: Sage.

Aubrey, J. S., Harrison, K., Kramer, L., \& Yellin, J. (2003). Variety versus timing: Gender differences in college students' sexual expectations as predicted by exposure to sexually oriented television. Communication Research, 30, 432-460.

Brosius, H-B., Weaver, J. B., \& Staab, J. F. (1993). Exploring the social and sexual reality of contemporary pornography. Journal of Sex Research, 30, 161-170.

Brown, J. D. (2000). Adolescents' sexual media diets. Journal of Adolescent Health, 27S, 35-40.

Brown, J. D., L'Engle, K. L., Pardun, C. J., Guo, G., Kenneavy, K., \& Jackson, C. (2006). Sexy media matter: Exposure to sexual content in music, movies, television, and magazines predicts Black and White adolescents' sexual behavior. Pediatrics, 117, 1018-1027.

Carpenter, L. M. (1998). From girls into women: Scripts for sexuality and romance in Seventeen magazine, 1974-1994. Journal of Sex Research, 35, 158-168.

Cooper, A. (1998). Sexuality and the Internet: Surfing into the new millennium. Cyberpsychology \& Behavior, 1, 181-187.

Cowan, G., Lee, C., Levy, D., \& Snyder, D. (1988). Dominance and inequality in X-rated videocassettes. Psychology of Women Quarterly, 12, 299-311.

Donnerstein, E., \& Smith, S. (2001). Sex in the media: Theory, influences, and solutions. In D. G. Singer \& J. L. Singer (Eds.), Handbook of children and the media (pp. 289-307). Thousand Oaks, CA: Sage.

Drenth, J. J., \& Slob, A. K. (1997). Netherlands and the autonomous Dutch Antilles. In R. T. Francoeur (Ed.), The international 
encyclopedia of sexuality (Vol. 2, pp. 895-961). New York: Continuum.

Ertel, H. (1990). Erotika und Pornographie: Repräsentative Befragung und psychophysiologische Langzeitstudie zu Konsum und Wirkung [Erotica and pornography. Representative survey and psycho-physiological longitudinal study on the consumption and effects of pornography]. Munich, Germany: PVU.

Escobar-Chaves, S. L., Tortolero, S. R., Markham, C. M., Low, B. J., Eitel, P., \& Thickstun, P. (2005). Impact of the media on adolescent sexual attitudes and behaviors. Pediatrics, 116, 303-326.

Fredrickson, B. L., \& Roberts, T-A. (1997). Objectification theory: Toward understanding women's lived experiences and mental health risks. Psychology of Women Quarterly, 21, 173-206.

Freeman-Longo, R. E. (2000). Children, teens, and sex on the Internet. Sexual Addiction and Compulsivity, 7, 75-90.

Glick, P., Lameiras, M., \& Castro, Y. R. (2002). Education and Catholic religiosity as predictors of hostile and benevolent sexism toward women and men. Sex Roles, 47, 433-441.

Grauerholz, E., \& King, A. (1997). Prime time sexual harrassment. Violence Against Women, 3, 129-148.

Greenberg, B. S., Siemicki, M., Heeter, C., Stanley, C., Soderman, A., \& Linsangan, R. (1993). Sex content in R-rated films viewed by adolescents. In B. S. Greenberg, J. D. Brown, \& N. BuerkelRothfuss (Eds.), Media, sex, and the adolescent (pp. 45-58). Cresskill, NJ: Hampton.

Greenfield, P. M. (2004). Inadvertent exposure to pornography on the Internet: Implications of peer-to-peer file-sharing networks for child development and families. Journal of Applied Developmental Psychology, 25, 741-750.

Krassas, N. R., Blauwkamp, J. M., \& Wesselink, P. (2001). Boxing Helena and corseting Eunice: Sexual rhetoric in Cosmopolitan and Playboy magazines. Sex Roles, 44, 751-771.

Kunkel, D., Eyal, K., Finnerty, K., Biely, E., \& Donnerstein, E. (2005). Sex on TV 4. Menlo Park, CA: Kaiser Family Foundation.

Lanis, K., \& Covell, K. (1995). Images of women in advertisements: Effects on attitudes related to sexual aggression. Sex Roles, 32, 639-649.

Le Gall, A., Mullet, E., \& Shafighi, S. R. (2002). Age, religious beliefs, and sexual attitudes. Journal of Sex Research, 39, 207-216.

L'Engle, K. L., Brown, J. D., \& Kenneavy, K. (2006). The mass media are an important context for adolescents' sexual behavior. Journal of Adolescent Health, 38, 186-192.

Lerner, R. M., \& Castellino, D. R. (2002). Contemporary developmental theory and adolescence: Developmental systems and applied developmental science. Journal of Adolescent Health, 31, 122-135.

Lo, V-h., \& Wei, R. (2005). Exposure to internet pornography and Taiwanese adolescents' sexual attitudes and behavior. Journal of Broadcasting \& Electronic Media, 49, 221-237.

MacKay, N. J., \& Covell, K. (1997). The impact of women in advertisements on attitudes toward women. Sex Roles, 36, 573-583.

Miller, B. C., Christopherson, C. R., \& King, P. K. (1993). Sexual behavior in adolescence. In T. P. Gullotta, G. R. Adams, \& R. Montemayor (Eds.), Adolescent sexuality (pp. 57-76). Newbury Park, CA: Sage.

Mitchell, K. J., Finkelhor, D., \& Wolak, J. (2003). The exposure of youth to unwanted sexual material on the Internet. A national survey of risk, impact, and prevention. Youth \& Society, 34, 330-358.

Mustanski, B. S. (2001). Getting wired: Exploiting the Internet for the collection of sexually valid data. Journal of Sex Research, 38, 292-301.

Pardun, C. J., L'Engle, K. L., \& Brown, J. D. (2005). Linking exposure to outcomes: Early adolescents' consumption of sexual content in six media. Mass Communication \& Society, 8, 75-91.

Paul, P. (2005). Pornified: How pornography is transforming our lives, our relationships, and our families. New York: Times.

Peter, J. (2004). Our long 'return to the concept of powerful mass media': A cross-national comparative investigation of the effects of consonant media coverage. International Journal of Public Opinion Research, 16, 144-168.

Peter, J., \& Valkenburg, P. M. (2006). Adolescents' exposure to sexually explicit material on the internet. Communication Research, 33, 178-204.

Petersen, A. C., Crockett, L., Richards, M., \& Boxer, A. (1988). A self-report measure of pubertal status: Reliability, validity, and initial norms. Journal of Youth and Adolescence, 17, 117-133.

Qrius (2005). Jongeren 2005. Het speelveld verandert [Youth 2005. The playing ground is changing]. Amsterdam: Qrius.

Rich, M., \& Bar-On, M. (2001). Child health in the information age: Media education of pediatricians. Pediatrics, 107, 156-162.

Roberts, D. F., Foehr, U. G., \& Rideout, V. (2005). Generation M: Media in the lives of 8-18 year olds. Menlo Park, CA: Kaiser Family Foundation.

Rutgers Nisso Group (2005). Seks onder je 25e [Sex before 25]. Retrieved August 29, 2005, from http://www.seksonderje25e.nl/ resultaten.

Scott, J. E. (1986). An updated longitudinal content analysis of sex references in mass circulation magazines. Journal of Sex Research, 22, 385-392.

Seidman, S. A. (1992). An investigation of sex-role stereotyping in music videos. Journal of Broadcasting \& Electronic Media, 36, 209-216.

Strasburger, V. C., \& Donnerstein, E. (1999). Children, adolescents, and the media: Issues and solutions. Pediatrics, 103, 129-139.

Strouse, J. S., \& Buerkel-Rothfuss, N. (1995). Gender and family as moderators of the relationship between music video exposure and adolescent sexual permissiveness. Adolescence, 30, 505-521.

Strouse, J. S., Goodwin, M. P., \& Roscoe, B. (1994). Correlates of attitudes toward sexual harassment among early adolescents. Sex Roles, 31, 559-577.

Thornburgh, D., \& Lin, H. S. (2002). Youth, pornography, and the Internet. Washington, DC: National Academy.

Townsend, J. M. (1993). Sexuality and partner selection: Sex differences among college students. Ethology and Sociobiology, 14, 305-329.

Unicef (2001). A league table of teenage births in rich nations (Innocenti report card no. 3, July 2001). Retrieved August 30, 2005, from http://www.unicef-icdc.org/publications/pdf/ repcard3e.pdf.

United Nations Development Programme (2001). Human development report 2001. New York: Oxford University Press.

Valkenburg, P. M., \& Janssen, S. C. (1999). What do children value in entertainment programs? A cross-cultural investigation. Journal of Communication, 49, 3-21.

Valkenburg, P. M., \& Peter, J. (2007). Preadolescents' and adolescents' online communication and their closeness to friends. Developmental Psychology. (in press)

Ward, L. M. (2002). Does television exposure affect emerging adults' attitudes and assumptions about sexual relationships? Correlational and experimental confirmation. Journal of Youth and Adolescence, 31, 1-15.

Ward, L. M. (2003). Understanding the role of entertainment media in the sexual socialization of American youth: A review of empirical research. Developmental Review, 23, 347-388.

Ward, L. M., \& Friedman, K. (2006). Using TV as a guide: Associations between television viewing and adolescents' sexual attitudes and behavior. Journal of Research on Adolescence, 16, 133-156.

Ward, L. M., \& Rivadeneyra, R. (1999). Contributions of entertainment television to adolescents' sexual attitudes and expectations: The role of viewing amount versus viewer involvement. Journal of Sex Research, 36, 237-249.

Zillmann, D., \& Bryant, J. (1986). Shifting preferences in pornography consumption. Communication Research, 13, 560-578.

Zillmann, D., \& Bryant, J. (1988). Effects of prolonged consumption of pornography on family values. Journal of Family Issues, 9, $518-544$ 